\title{
RELAÇÃO ENTRE PRODUÇÃO E DEMANDA HÍDRICA NA BACIA DO RIO UBERABINHA, ESTADO DE MINAS GERAIS, BRASIL
}

\section{Relationship between production and demand water in the Uberabinha watershed, State of Minas Gerais, Brazil}

\author{
Arlei Teodoro de Queiroz \\ Mestre em Geografia pela Universidade Federal de Uberlândia \\ arleiteodoro@yahoo.com.br \\ Luiz Antonio de Oliveira \\ Prof. Adjunto, Instituto de Geografia, UFU \\ luizantonio@ig.ufu.br
}

Artigo recebido em 17/08/2012 e aceito para publicação em 29/01/2013

RESUMO: A compreensão das fases do ciclo hidrológico é essencial em estudos hidrológicos. Neste sentido este trabalho tem como objetivo analisar a relação entre produção e demanda de água na Bacia Hidrográfica do Rio Uberabinha, utilizando-se dados de vazão da estação fluviométrica Fazenda Letreiro (Agencia Nacional de Águas - ANA, código 60381000), série histórica de 1976 a 2006 e de outorga superficial do IGAM. No tratamento estatístico dos dados foi utilizada a distribuição de Gumbel para eventos extremos e análises matemáticas no software Siscah. Análise da relação entre a produção e consumo demonstra que a produção hídrica não é insuficiente para atender a demanda. $\mathrm{O}$ volume outorgado é de $3,4 \mathrm{~m}^{3} / \mathrm{s}$, no entanto, análise estatística do período de retorno, indica que a cada 14 anos ocorra uma vazão mínima igual ou inferior a $3,4 \mathrm{~m}^{3} / \mathrm{s}$, confirmando a situação de escassez hídrica na bacia analisada. A partir dos resultados obtidos neste trabalho pode-se concluir que é necessário um plano de gestão de recursos hídricos para a área de estudos, viabilizando assim o manejo adequado das atividades econômicas utilizadoras de água e a participação de todos os usuários de água da bacia.

Palavras-chave: Bacia do Rio Uberabinha; eventos extremos; outorga.

\begin{abstract}
Understanding of phases of hydrological cycle is essential in hydrologic studies. In this sense, this work search analyze the relationship between production and demand for water in Uberabinha watershed, state of Minas Gerais, using water flow data derived from Fazenda Letreiro fluviometric station (National Water Agency - ANA code 60381000), time series from 1976 to 2006 and water demand of the water rights permits, warranted by the government - IGAM. In the statistical treatment of data was used Gumbel distribution for extreme events and mathematical analysis Siscah software. Analysis of the relationship between water production and the volume given shows that the production is insufficient to meet demand. The volume given is $3,4 \mathrm{~m}^{3} / \mathrm{s}$, however, statistic analysis of return period indicates that every fourteen years there is a minimum flow rate equal to or less than $3,4 \mathrm{~m}^{3} / \mathrm{s}$, confirming the situation of water scarcity in the watershed analyzed. From the results obtained in this work can be concluded that a management plan for water resources is necessary in the study area, thus enabling management of the economics activities water uses and a more effective participation of water users sectors of the watershed.
\end{abstract}

Keywords: Uberabinha Watershed; extreme events, water rights permits 


\section{INTRODUÇÃO}

Com a crescente demanda por água, sobretudo após meados do século XX, devido ao fato deste ser o principal recurso natural que propiciou importante incremento a produção tanto no espaço rural como no urbano. Dentre as atividades que demandam grande quantidade de água, merecem destaque a agricultura, $o$ abastecimento público de água em ambientes urbanos e as indústrias com grande consumo deste recurso.

Diante deste aumento significativo na demanda por água, tornou eminente em vários locais a disputa por este recurso gerando problemas relacionados a quantidade e a qualidade das águas disponíveis para tais usos. Tal situação culminou na necessidade de realização várias pesquisas científicas buscando analisar e otimizar o uso deste recurso, sendo estas, ferramentas essenciais para melhor gestão dos recursos hídricos.

Como ponto de partida de estudos hidrológicos, é primordial a compreensão da dinâmica da água no planeta, ou seja, entender o ciclo hidrológico, sendo que este pode ser definido como o movimento da água no planeta, bem como suas mudanças de estado durante este movimento.

Para melhor compreensão deste ciclo pode-se visualizá-lo como tendo início com a evaporação da água dos oceanos. O vapor resultante é transportado pelo movimento das massas de ar. Sob determinadas condições, o vapor é condensado, formando as nuvens que por sua vez podem resultar em precipitação. A precipitação que ocorre sobre a terra é dispersada de várias formas. A maior parte fica temporariamente retida no solo próximo de onde caiu e finalmente retorna à atmosfera por evaporação e transpiração das plantas. Uma parte da água restante escoa sobre a superfície do solo, ou através do solo para os rios, enquanto que a outra parte, penetrando profundamente no solo, vai suprir o lençol d'água subterrâneo.

Devido à influência da gravidade, tanto o escoamento superficial como subterrâneo são realizados em direção a cotas mais baixas e podem, eventualmente, ser descarregados nos oceanos. Entretanto, quantidades substanciais da água superficial e subterrânea retornam à atmosfera por evaporação e transpiração antes de atingirem o oceano (VILLELA; MATTOS, 1975, p. 1).

No contexto do ciclo hidrológico, neste trabalho será tratado apenas o escoamento superficial fluvial, podendo este ser definido como o fluxo de água no leito dos rios, sendo resultado, principalmente, dos escoamentos superficial e subterrâneo. A água que escoa no leito das drenagens são denominadas "águas sujeitas", sendo dependente de mais de uma fase do ciclo hidrológico, conforme foi descrito por Pinto et al (1976):

À medida que as águas vão atingindo os pontos mais baixos do terreno, passam a escoar em canalículos que formam a microrrede de drenagem. Sob a ação da erosão, vai aumentando a dimensão desses canalículos e o escoamento se processa, cada vez mais, por caminhos preferenciais. Formam-se as torrentes, cuja duração está associada, praticamente, à precipitação; a partir delas, formam-se os cursos de água propriamente ditos, com escoamento dependendo da água superficial e da contribuição do lençol de água subterrânea. (PINTO et al, 1976, p. 36-37).

Sobre o escoamento superficial fluvial, vale destacar que, devido a facilidade de acesso a água, este torna-se a principal fonte de abastecimento dos diversos setores usuários. Neste sentido, com o objetivo de melhorar a gestão deste recurso e seguindo experiências bem sucedidas em outros países, em 1997 no Brasil foi instuída a Política Nacional de Recursos Hídricos, que tem dentre seus instrumentos a outorga dos direitos de uso de recursos hídricos, que visa estabelecer um controle da quantidade e a demanda de água numa bacia hidrográfica.

A outorga de uso da água é um instrumento básico da gestão de recursos hídricos. Seja qual for a forma utilizada para o outorga de direitos de uso (permissões, licenças ou 
outra forma legal de fornecer capacidades de utilização da água), ela se fundamenta em bases técnicas, legais, econômicas e sociais. Os sistemas de outorga têm uma importância relevante, com ou sem mercados de água, dado que se constituem na fonte de informação e registro das transações de água, independente do mecanismo que tal transação se executa (CEPAL, 1994). A informação dos volumes utilizados e de seu regime de uso é fundamental para o conhecimento da disponibilidade hídrica, pois os usos afetam as séries hidrológicas. (CRUZ, 2001, p. 35).

De acordo com Silveira et al. (1998) "para estabelecer a relação entre disponibilidade versus demanda de água, são necessários desenvolver estudos hidrológicos que maximizem as informações hidrometeorológicas disponíveis e ainda o levantamento dos usuários atuais dos recursos hídricos em captações ou despejo de efluentes."

Neste sentido, este trabalho tem o objetivo de analisar a relação entre produção e demanda de água na Bacia Hidrográfica do Rio Uberabinha, à montante da estação fluviométrica Fazenda Letreiro, municípios de Uberaba e Uberlândia/MG, utilizando-se dados de vazão da referida fluviométrica e ainda informações de outorgas superficiais. Justifica-se o uso desta estação pelo fato de ser a única existente na bacia de estudos, sendo também a única fonte de dados que contempla uma série histórica significativa.

\section{LOCALIZAÇÃO E CARACTERIZAÇÃO DA ÁREA}

A área de estudos se encontra delimitada pelas coordenadas de $48^{\circ} 12^{\prime} 45^{\prime \prime} \mathrm{W} / 18^{\circ} 56^{\prime} 11^{\prime \prime} \mathrm{S}$ e longitude 47 $49^{\prime} 55^{\prime}$ 'W/19²6' $42^{\prime}$ ' S, ocupando parte dos municípios de Uberaba e Uberlândia/MG (figura 1).

A área drenada pelo Rio Uberabinha, a montante da Fazenda Letreiro, corresponde a um total de $790 \mathrm{~km}^{2}$. O rio Uberabinha é afluente da margem esquerda do rio Araguari, que por sua vez está inserido na Bacia do Rio Paranaíba.

Segundo a classificação de Köppen, adotada universalmente e adaptada ao Brasil, o clima de área de estudos se insere na classificação Aw, ou seja, o inverno é seco e o verão chuvoso com predominância dos sistemas intertropicais e polares. A precipitação média anual é de $1550 \mathrm{~mm}$ e temperatura de $22.5^{\circ}$. Com relação especificamente a temperatura, os meses com as menores médias são maio, junho e julho enquanto os de maiores médias são setembro e outubro. Analisando a precipitação, os meses mais chuvosos são dezembro e janeiro, enquanto que o período de maior estiagem se estende de junho a agosto.

A Geologia se caracteriza pela sequência vulcano-sedimentar com rochas de idade cretácea e cenozoica. Os basaltos da formação Serra Geral, de idade cretácea, ocorrem em cotas de até $840 \mathrm{~m}$ de altitude e constituem o nível de base local. Sobrepostos aos basaltos ocorrem os arenitos da Formação Marília, Grupo bauru, Cretáceo Superior, ocupando as áreas de topo, em feições de relevos planos a suavemente ondulados (OLIVEIRA; CAMPOS, 2004).

De acordo com Costa (2009) e seguindo a classificação da Embrapa (2006), os solos predominantes na área de estudo são os latossolos vermelhos, distroférricos ou eutroférricos, sendo que o primeiro ocorre sobre os arenitos ou basaltos e o segundo ocorre somente sobre os basaltos. Em áreas mal drenadas, junto às drenagens e junto aos covoais ocorrem os gleissolos.

Sobre o relevo, o gradiente topográfico é de 220 metros, com cotas variando de 830 a $1050 \mathrm{~m}$ de altitude. Com relação da declividade, a maioria da área possui feições planas a suavemente onduladas. Na parte alta da bacia, nos interflúvios, as declividades não excedem os $2 \%$, enquanto que valores maiores, com até $12 \%$ ocorrem ao longo dos vales das drenagens principais, médio-curso do rio Uberabinha e do ribeirão Beija-Flor. 
Figura 1. Área de pesquisa

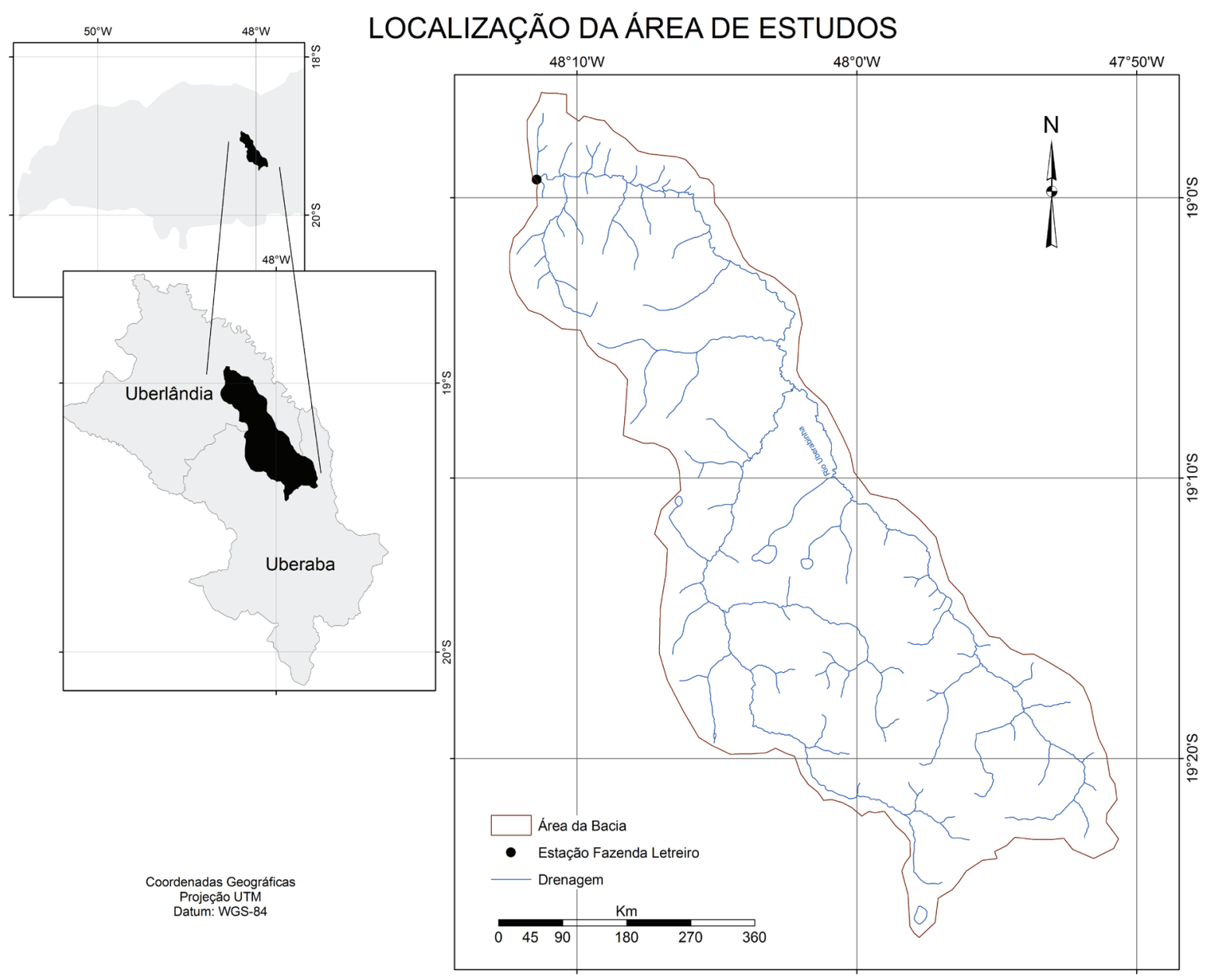

Elaboração dos autores.

Baccaro (1989) caracterizou a geomorfologia em três categorias: área de relevo intensamente dissecado e área de relevo com topo plano, com predomínio da última categoria. Nishiyama (1998) descreveu o relevo da área de estudos nos seguintes compartimentos: colinas amplas com encostas convexas e superfícies aplanadas. As colinas amplas com encostas convexas acompanham os principais cursos de água (Uberabinha, Beija-Flor) desde próximo de suas nascentes, ampliando sua área a medida que se aproxima com confluência do rio Uberabinha e ribeirão Bom Jardim. As superfícies aplanadas localizam-se nos interflúvios com topos planos, com vasta área de chapada, sobretudo no alto curso do rio Uberabinha e ribeirões Beija-flor.

Ainda sobre a geomorfologia, Feltran Filho
(1997) faz um esboço, compartimentando as chapadas em unidades geomorfológicas da bacia do Beija-Flor, Uberlândia e alto Uberabinha. De acordo com o autor, a unidade geomorfológica da "Bacia do ribeirão Beija-Flor" possui drenagem padrão dendrítico e densa e cobertura de latossolo Vermelho-Escuro. Nota-se nesta unidade, também:

[...] a existência de terraços fluviais podem ser observados no contato entre a cobertura sedimentar e a soleira basáltica, pontos em que os vales tornam-se mais largos e as vertentes, se afastando, dão lugar a terraços com depósitos de sedimentos mais grosseiros, com cascalho. Associam-se a esses depósitos, fora do plano de inundação, blocos conglomeráti- 
cos formados por seixos de quartzo e quartzitos, cimentados por material ferruginoso, talvez restos de horizontes mais resistentes, em decomposição (FELTRAN FILHO, 1997, p. 166).

A unidade geomorfológica "Uberlândia", conforme descreve Feltran Filho:

Possui na parte oeste suas maiores altitudes, fazendo com que a drenagem da unidade tenha sentido geral oeste-leste direcionada para a bacia do Uberabinha. Com forte controle estrutural, a rede de drenagem exibe padrão geométrico, como por exemplo, apresentando desvios bruscos e retilíneos na mudança de direção dos rios nas partes mais elevadas dos topos formados por sedimentos da Formação Marília. (FELTRAN FILHO, 1997, p. 167).

A unidade geomorfológica "Alto Uberabinha "É caracterizada por topografias elevadas e planas. Seus interflúvios tabulares apresentam simetria no perfil transversal e longitudinal, e seus divisores são de difícil precisão" (FELTRAN FILHO, 1997, p. 170).

\section{OBJETIVO}

O Objetivo principal deste trabalho é analisar a relação entre produção e demanda de água na Bacia Hidrográfica do Rio Uberabinha, à montante da estação fluviométrica Fazenda Letreiro, municípios de Uberaba e Uberlândia/MG, utilizando-se dados de vazão da referida fluviométrica e ainda informações de outorgas superficiais.

\section{MÉTODOS}

Para a realização do presente trabalho foram utilizados dados de vazão da série histórica de 1976 a 2006 da estação fluviométrica Fazenda Letreiro, código Agência Nacional de Águas - ANA 60381000, localizada na Fazenda Letreiro, cujas coordenadas geográficas são $18^{\circ} 59^{\prime} 18^{\prime \prime} \mathrm{S}$ e $48^{\circ} 11^{\prime} 25^{\prime}$ 'W e altitude de 800 metros. Esta estação se encontra à jusante da captação da Estação de Tratamento de Água - ETA - Sucupira, responsável por parte do abastecimento urbano de Uberlândia.

Vale destacar que a ANA e o CPRM (Serviço Geológico do Brasil), trabalhando em conjunto, são os principais e, em grande parte do país, os únicos órgãos brasileiros responsáveis pela operação e monitoramento dos dados hidrológicos no território nacional, disponibilizando os resultados em um banco de dados consistente, que foi utilizado para a realização deste trabalho.

Para tabulação e apresentação gráfica dos dados foram utilizados os softwares Microsoft Office Excel e Sistema Computacional para Análises Hidrológicas (Siscah 1.0) desenvolvido pela Universidade Federal de Viçosa (UFV). Além dos dados fluviométricos, disponibilizados pela ANA, foram utilizados, dados referentes a outorgas superficiais e volume outorgado na bacia do Uberabinha, disponibilizados pelo Instituto Mineiro de Gestão das Águas (IGAM).

Dentre as grandezas características do escoamento superficial fluvial será analisada, mais especificamente a vazão $(\mathrm{Q})$, que pode ser definida como o volume de água escoado por unidade de tempo em um determinado ponto do curso de água, sendo que normalmente ela é expressa em metros cúbicos por segundo $\left(\mathrm{m}^{3} / \mathrm{s}\right)$ ou litros por segundo $(1 / \mathrm{s})$.

A análise estatística de dados quantitativos referente a recursos hídricos se torna essencial para a compreensão da disponibilidade hídrica de uma bacia hidrográfica.

A análise preliminar de uma amostra de dados hidrológicos compreende um conjunto de métodos e técnicas que visam extrair as características empíricas essenciais do padrão de distribuição de uma variável hidrológica. Esse conjunto pode ser dividido em três grupos: (a) Apresentação Gráfica de Dados Hidrológicos; (b) Sumário Numérico e Estatísticas Descritivas e (c) Métodos Exploratórios. (NAGHETTINI; PINTO, 2007, p. 19).

Neste trabalho, no tratamento dos dados será aplicada estatística descritiva que, de acordo com Naghettini e Pinto (2007, p.30), "pode ser agrupada 
em 3 tipos distintos: (a) medidas de tendência central; (b) medidas de dispersão e (c) medidas de assimetria e de curtose".

No que diz respeito às medidas de tendência central, três tipos são muito conhecidas na hidrologia, que são a média, a moda e a mediana. A tendência central:

[...] é relacionada com a parte central do histograma de frequências. Existe, às vezes, uma tendência de que o número de ocorrências seja maior nesta parte central, significando que a variável aleatória costuma ocorrer com maior frequência no intervalos centrais (LANNA, 2009, p. 91).

Segundo Lima (2010, p. 5-6), a média aritmética "é obtida simplesmente pela relação entre a soma dos valores e o número total " $n$ " de dados de uma amostra". A mediana é um valor central entre os dados que compõe a amostra, sendo que, metade dos dados está acima desse valor e a outra abaixo, não sendo necessariamente, o meio caminho entre o maior e o menor valor. A moda está associada ao valor mais frequente, ou que mais se repete, dos dados que compõe a amostra.

Ainda sobre as estatísticas descritivas, valem destacar também as medidas de dispersão como a amplitude, a variância e o desvio-padrão. A amplitude é a diferença entre o valor máximo e mínimo de uma amostra. "A variância e o desvio padrão são estatísticas que nos fornecem uma idéia de variabilidade das observações em torno da média aritmética." (GUIMARÃES, 2004, p.4)

Além da análise preliminar de uma amostra de dados hidrológicos, descrita acima, é importante para o conhecimento hidrológico a aplicação de modelos probabilísticos, voltados para o tema.

Para extrair conclusões de uma amostra de dados hidrológicos, que sejam úteis à tomada de decisões no planejamento e projeto de sistemas de recursos hídricos, é necessário estabelecer um modelo matemático que contenha os principais elementos do processo hidrológico que determinou a ocorrência daquelas observações. [...].

Um modelo probabilístico, embora seja inca- paz de prever com exatidão a data e a magnitude de uma enchente, por exemplo, revela-se muito útil no estudo do regime local de cheias, especificando com que probabilidade uma certa vazão irá ser igualada ou superada, em um ano qualquer (NAGHETTINI; PINTO, 2007, p. 53).

A maioria dos modelos probabilísticos existentes em hidrologia utiliza a distribuição de Gumbel, onde se analisa os eventos extremos (vazões máximas e mínimas). Os resultados destas análises permitem entender o comportamento hidrológico da drenagem em análise, principalmente a predição dos eventos de cheias e de escassez hídrica. Estes dados são de suma importância no dimensionamento de obras hidráulicas (barragens, pontes, galerias, dentre outras) e ainda no planejamento da distribuição da água em períodos de escassez.

A lei de distribuição de frequências de Gumbel é utilizada para o estudo dos valores extremos. A probabilidade de que se encontre um valor inferior a um determinado evento " $X$ " pode ser calculado pela fórmula:

$$
\begin{aligned}
& F(x)=e^{-e^{-b}} \\
& \text { Onde: } \\
& e=\text { base dos logaritmos neperianos. } \\
& \text { Para se calcular } b \text {, utiliza-se a expressão: } \\
& b=\alpha(x-u) \\
& \text { Onde: } \\
& x=\text { valor do evento à ser superado. } \\
& \text { Para se calcular } \alpha \text {, utiliza-se a expressão: } \\
& \alpha=\sigma_{y} / s_{x} \\
& \text { Onde: } \\
& \sigma_{y}=\text { é a média de uma série de valores } \mathrm{y}_{\mathrm{i}}(\mathrm{i}=1
\end{aligned}
$$

a $\mathrm{N} ; \mathrm{N}=$ nr de dados da amostra) que depende somente do número de dados. Valores encontram-se na tabela 1.

$$
S_{x}=\text { desvio padrão da amostra }
$$

Para se calcular $\mu$, utiliza-se a expressão:

$u=\bar{x}-\mu_{y} u=\bar{x}-\mu_{y} / \alpha$

Onde:

$\overline{\mathrm{x}}=$ média aritmética da amostra

$\mu_{\mathrm{y}}=$ é o desvio padrão de uma série de valores $\mathrm{y}_{\mathrm{i}}(\mathrm{i}=1 \mathrm{a} \mathrm{N} ; \mathrm{N}=\mathrm{nr}$ de dados da amostra) que depende somente do número de dados. Valores encontram-se na tabela 1 . 
Tabela 1 - Valores da média $\left(\gamma_{\mathrm{n}}\right)$ e do desvio-padrão $\left(\mathrm{S}_{\mathrm{n}}\right)$ da variável reduzida em função do tamanho da amostra $(\mathrm{n})$.

\begin{tabular}{ccc|ccc|ccc}
\hline $\mathrm{n}$ & $\gamma_{\mathrm{n}}$ & $\mathrm{S}_{\mathrm{n}}$ & $\mathrm{n}$ & $\gamma_{\mathrm{n}}$ & $\mathrm{S}_{\mathrm{n}}$ & $\mathrm{n}$ & $\gamma_{\mathrm{n}}$ & $\mathrm{S}_{\mathrm{n}}$ \\
\hline 10 & 0,4967 & 0,9573 & 45 & 0,5463 & 1,1519 & 73 & 0,5555 & 1,1881 \\
15 & 0,5128 & 1,0206 & 46 & 0,5468 & 1,1538 & 74 & 0,5557 & 1,1890 \\
20 & 0,5236 & 1,0628 & 47 & 0,5473 & 1,1557 & 75 & 0,5559 & 1,1898 \\
21 & 0,5252 & 1,0696 & 48 & 0,5477 & 1,1574 & 76 & 0,5561 & 1,1906 \\
22 & 0,5268 & 1,0754 & 49 & 0,5481 & 1,1590 & 77 & 0,5563 & 1,1915 \\
23 & 0,5283 & 1,0811 & 50 & 0,5485 & 1,1607 & 78 & 0,5565 & 1,1923 \\
24 & 0,5296 & 1,0864 & 51 & 0,5489 & 1,1623 & 79 & 0,5567 & 1,1930 \\
25 & 0,5309 & 1,0915 & 52 & 0,5493 & 1,1638 & 80 & 0,5569 & 1,1938 \\
26 & 0,5320 & 1,0961 & 53 & 0,5497 & 1,1658 & 81 & 0,5570 & 1,1945 \\
27 & 0,5332 & 1,1004 & 54 & 0,5501 & 1,1667 & 82 & 0,5572 & 1,1953 \\
28 & 0,5343 & 1,1047 & 55 & 0,5504 & 1,1681 & 83 & 0,5574 & 1,1960 \\
29 & 0,5353 & 1,1086 & 56 & 0,5508 & 1,1696 & 84 & 0,5576 & 1,1967 \\
30 & 0,5362 & 1,1124 & 57 & 0,5511 & 1,1708 & 85 & 0,5578 & 1,1973 \\
31 & 0,5371 & 1,1159 & 58 & 0,5515 & 1,1721 & 86 & 0,5580 & 1,1980 \\
32 & 0,5380 & 1,1193 & 59 & 0,5518 & 1,1734 & 87 & 0,5581 & 1,1987 \\
33 & 0,5388 & 1,1226 & 60 & 0,5521 & 1,1747 & 88 & 0,5583 & 1,1994 \\
34 & 0,5396 & 1,1255 & 61 & 0,5524 & 1,1759 & 89 & 0,5585 & 1,2001 \\
35 & 0,5403 & 1,1285 & 62 & 0,5527 & 1,1770 & 90 & 0,5586 & 1,2007 \\
36 & 0,5410 & 1,1313 & 63 & 0,5530 & 1,1782 & 91 & 0,5587 & 1,2013 \\
37 & 0,5418 & 1,1339 & 64 & 0,5533 & 1,1793 & 92 & 0,5589 & 1,2020 \\
38 & 0,5424 & 1,1363 & 65 & 0,5535 & 1,1803 & 93 & 0,5591 & 1,2026 \\
39 & 0,5430 & 1,1388 & 66 & 0,5538 & 1,1814 & 94 & 0,5592 & 1,2032 \\
40 & 0,5436 & 1,1413 & 67 & 0,5540 & 1,1824 & 95 & 0,5593 & 1,2038 \\
41 & 0,5442 & 1,1436 & 68 & 0,5543 & 1,1834 & 96 & 0,5595 & 1,2044 \\
42 & 0,5448 & 1,1458 & 69 & 0,5545 & 1,1844 & 97 & 0,5596 & 1,2049 \\
43 & 0,5453 & 1,1480 & 70 & 0,5548 & 1,1854 & 98 & 0,5598 & 1,2055 \\
44 & 0,5458 & 1,1499 & 71 & 0,5550 & 1,1863 & 99 & 0,5599 & 1,2060 \\
& & & 72 & 0,5552 & 1,1873 & 100 & 0,5600 & 1,2065 \\
\hline
\end{tabular}

Fonte: CARVALHO; SILVA, 2006

Dentre os modelos probabilísticos, destaca-se o cálculo do período de retorno, usado para dimensionamento da capacidade de suporte de obras culturais, sendo expresso como "[...] o significado de que, na seção considerada, ocorrerão valores iguais ou superiores ao valor "Q" apenas uma vez cada "T" anos", sendo utilizado sobretudo em estudos estatísticos de eventos extremos (máximas e mínimas), (PINTO et al, 1976, p. 38),

A partir das expressões anteriores pode-se calcular a probabilidade de que um certo evento supere $\boldsymbol{x}$, é dizer que: calcular que frequência (ou período de retorno) se apresentará uma certa vazão ou precipitação.

Estimativas de frequências de vazões mínimas, baseadas em métodos estatísticos aplicados a séries de dados observados, possuem larga aplicação, principalmente em estudos de gerenciamento de qualidade de água (Boner e Furland, 1982; Rossman, 1989; Lence et al., 1990) e, modernamente, em avaliação de disponibilidades hidricas para uso quali- -quantitativo (CRUZ, 2001, p.24).

Para solucionar o caso inverso (que vazão ou precipitação se produzirão cada $n$ anos) devemos determinar (calcular) $\boldsymbol{b}$ na expressão (1), obtendo:
$b=-\ln (-\ln (F(x)))$
Onde:
$L n=$ logaritmo natural
E finalmente, calcular $x$ na equação (2):
$x=b / \alpha+u$

\section{RESULTADOS E DISCUSSÕES}

Aplicando a metodologia descrita, foi possível avaliar a produção e demanda hídrica na área analisada, cujos resultados para esta avaliação serão descritos no decorrer deste item.

Conforme já descrito no capítulo de métodos, pelo fato da estação fluviométrica Fazenda Letreiro se posicionar à jusante do ponto de captação de água para abastecimento público da cidade de Uberlândia, ETA Sucupira, os resultados descritos neste trabalho 
referem-se aos dados brutos de vazão registrados na respectiva estação, acrescentados dos valores outorgados e captados pela referida ETA, somados às demais captações outorgadas para usos na agropecuária. Portanto, aos valores registrados na fluviométrica foi somado o valor de $1,9 \mathrm{~m}^{3} / \mathrm{s}$ (captação ETA mais captação na agropecuária).
Os dados de vazões analisados, referentes à estação Fazenda Letreiro, eventos máximos e mínimos estão sumariados na tabela 2 , sendo possível verificar que dos 31 anos analisados, a vazão máxima foi de $175 \mathrm{~m}^{3} / \mathrm{s} \mathrm{em} 1985$, enquanto que a mínima foi de 0,90 $\mathrm{m}^{3} / \mathrm{s}$ em 1978 .

Tabela 2. Vazões extremas anuais (máximas e mínimas), estação Fazenda Letreiro

\begin{tabular}{|c|c|c|c|c|}
\hline Ano & Máximas & $\begin{array}{l}\text { Máximas com acréscimo da } \\
\text { vazão outorgada e captada }\end{array}$ & Mínimas & $\begin{array}{l}\text { Mínimas com acréscimo da } \\
\text { vazão outorgada e captada }\end{array}$ \\
\hline 1976 & 40,84 & 42,7 & 3,97 & 5,9 \\
\hline 1977 & 88,07 & 90,0 & 1,96 & 3,9 \\
\hline 1978 & 44,25 & 46,2 & 0,90 & 2,8 \\
\hline 1979 & 68,06 & 70,0 & 3,97 & 5,9 \\
\hline 1980 & 51,30 & 53,2 & 3,97 & 5,9 \\
\hline 1981 & 50,50 & 52,4 & 1,82 & 3,7 \\
\hline 1982 & 134,05 & 136,0 & 4,92 & 6,8 \\
\hline 1983 & 140,53 & 142,4 & 8,35 & 10,3 \\
\hline 1984 & 42,72 & 44,6 & 4,15 & 6,1 \\
\hline 1985 & 175,47 & 177,4 & 2,11 & 4,0 \\
\hline 1986 & 87,59 & 89,5 & 3,08 & 5,0 \\
\hline 1987 & 44,63 & 46,5 & 3,79 & 5,7 \\
\hline 1988 & 39,35 & 41,3 & 4,53 & 6,4 \\
\hline 1989 & 76,05 & 78,0 & 3,25 & 5,2 \\
\hline 1990 & 22,29 & 24,2 & 2,91 & 4,8 \\
\hline 1991 & 69,37 & 71,3 & 3,25 & 5,2 \\
\hline 1992 & 91,87 & 93,8 & 6,56 & 8,5 \\
\hline 1993 & 68,50 & 70,4 & 6,56 & 8,5 \\
\hline 1994 & 82,92 & 84,8 & 3,61 & 5,5 \\
\hline 1995 & 88,54 & 90,4 & 3,79 & 5,7 \\
\hline 1996 & 47,34 & 49,2 & 2,11 & 4,0 \\
\hline 1997 & 75,15 & 77,1 & 2,42 & 4,3 \\
\hline 1998 & 45,79 & 47,7 & 1,96 & 3,9 \\
\hline 1999 & 46,17 & 48,1 & 2,91 & 4,8 \\
\hline 2000 & 146,01 & 147,9 & 3,61 & 5,5 \\
\hline 2001 & 37,88 & 39,8 & 2,04 & 3,9 \\
\hline 2002 & 146,01 & 147,9 & 3,17 & 5,1 \\
\hline 2003 & 95,96 & 97,9 & 5,83 & 7,7 \\
\hline 2004 & 49,11 & 51,0 & 3,52 & 5,4 \\
\hline 2005 & 48,13 & 50,0 & 3,17 & 5,1 \\
\hline 2006 & 42,34 & 44,2 & 5,72 & 7,6 \\
\hline
\end{tabular}

Org. dos autores.

Os resultados a seguir sintetizam o tratamento dos eventos extremos, comportamento das vazões mínimas e máximas, utilizando-se a probabilidade de Gumbel.

Dentre os resultados dos cálculos estatísticos descritivos das vazões máximas diárias/ano, obteve-se que em média a vazão máxima anual é de $75,7 \mathrm{~m}^{3} / \mathrm{s}$, moda de $147,9 \mathrm{~m}^{3} / \mathrm{s}$ e a mediana de $70 \mathrm{~m}^{3} / \mathrm{s}$. Com relação às medidas de dispersão, a amplitude é de 153,2 $\mathrm{m}^{3} / \mathrm{s}$, variância de $1497,0 \mathrm{~m}^{3} / \mathrm{s}$, e o desvio-padrão de $38,7 \mathrm{~m}^{3} / \mathrm{s}$. Síntese dos resultados está sumariada na tabela 3 . 
Tabela 3 - Estatísticas descritivas da vazão máxima, estação Fazenda Letreiro

\begin{tabular}{ccc|ccc}
\hline \multicolumn{3}{c|}{ Medidas de tendência central } & \multicolumn{3}{c}{ Medidas de dispersão } \\
\hline Média & Moda & Mediana & Amplitude & Variância & Desvio-padrão \\
\hline 75,7 & 147,9 & 70,0 & 153,2 & 1497,0 & 38,7 \\
\hline \multicolumn{4}{c}{ Org. dos autores. }
\end{tabular}

A análise de eventos extremos, vazões máximas, é de suma importância no dimensionamento de obras de arte e hidráulicas ao longo do curso d' água objeto de estudo. A partir dos dados de vazão máxima diária/ano, foi calculado o período de retorno utilizando-se a distribuição de Gumbel para eventos máximos (Figura 2). Os valores de vazão com respectivos períodos de retorno esperados são: de 2 anos para uma vazão de $70 \mathrm{~m}^{3} / \mathrm{s}$; de 5 anos para uma vazão de 109 $\mathrm{m}^{3} / \mathrm{s}$; de 10 anos para uma vazão de $135 \mathrm{~m}^{3} / \mathrm{s}$; de 20 anos para uma vazão de $160 \mathrm{~m}^{3} / \mathrm{s}$; de 50 anos para uma vazão de $192 \mathrm{~m}^{3} / \mathrm{s}$, e de 100 anos para uma vazão de $217 \mathrm{~m}^{3} / \mathrm{s}$.

Figura 2 - Período de retorno de vazões máximas, estação Fazenda Letreiro

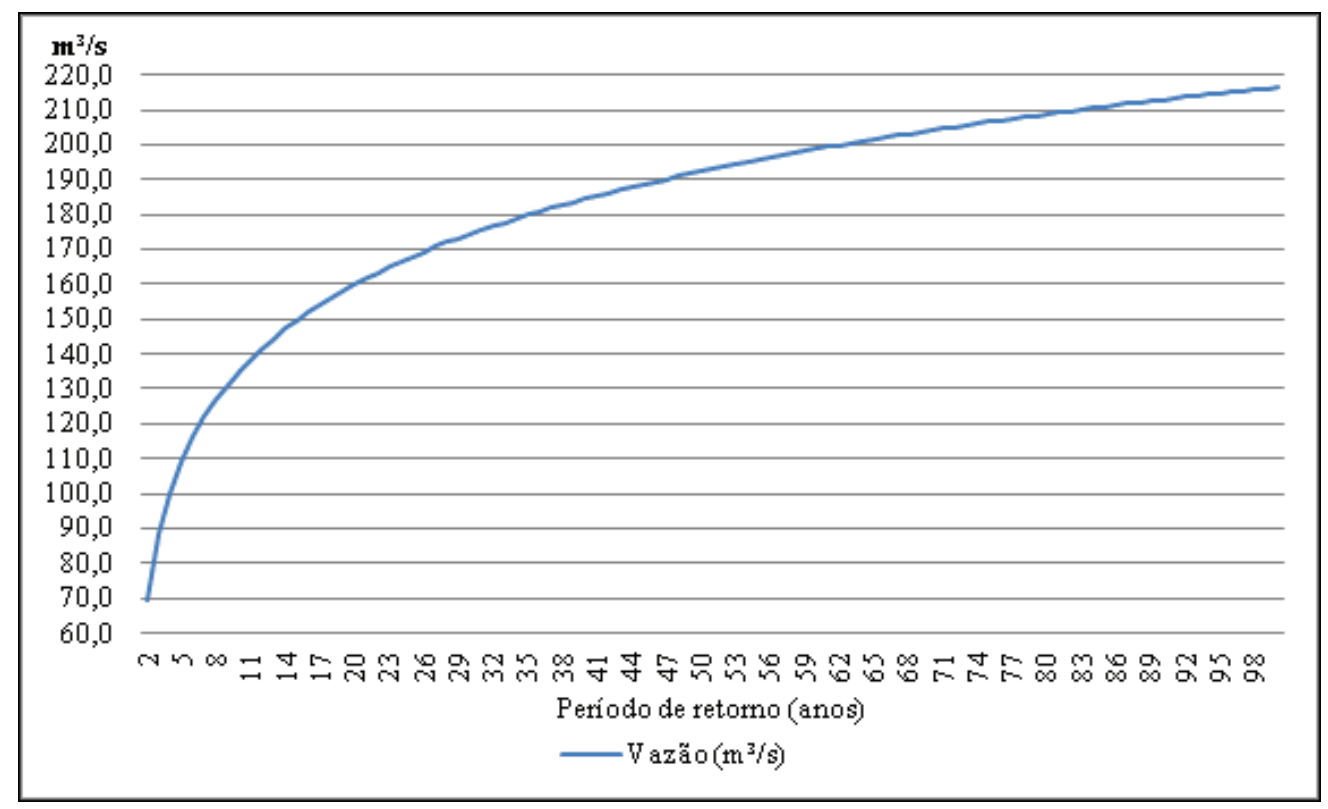

Org. dos autores.

A análise de dados referente à vazão mínima é importante na definição, de forma estatística, de períodos críticos, de escassez hídrica. Neste sentido, foram calculados os índices que podem auxiliar na tomada de decisão, quando de situação de conflitos pela água em períodos de escassez.

Com relação às medidas de centralização, a vazão mínima média calculada para o período analisado é de $5,6 \mathrm{~m}^{3} / \mathrm{s}$, mediana de $5,9 \mathrm{~m}^{3} / \mathrm{s}$ e a moda de $5,4 \mathrm{~m}^{3} / \mathrm{s}$. Para as medidas de dispersão têm-se uma amplitude de 7,5 m³/s, variância é 2,6 e desvio-padrão de $1,6 \mathrm{~m}^{3} / \mathrm{s}$. Os resultados dos cálculos das estatísticas descritivas das vazões mínimas estão sumariados na tabela 4. 
Relação entre produção e demanda hídrica na bacia do rio Uberabinha, estado de Minas Gerais, Brasil Arlei Teodoro de Queiroz, Luiz Antonio de Oliveira

Tabela 4. Estatísticas descritivas da vazão mínima, estação Fazenda Letreiro

\begin{tabular}{ccc|ccc}
\hline \multicolumn{3}{c|}{ Medidas de tendência central } & \multicolumn{3}{c}{ Medidas de dispersão } \\
\hline Média & Moda & Mediana & Amplitude & Variância & Desvio-padrão \\
\hline 5,6 & 5,9 & 5,4 & 7,5 & 2,6 & 1,6 \\
\hline
\end{tabular}

Com base nos dados de vazão mínima por ano foi calculado o período de retorno utilizando a distribuição de Gumbel para eventos mínimos (Figura 3). Os valores de vazão esperada e respectivo período de retorno são: de 2 anos para vazão de $5,3 \mathrm{~m}^{3} / \mathrm{s}$; de
5 anos para vazão de $4,1 \mathrm{~m} 3 / \mathrm{s}$; de 10 anos para vazão de $3,6 \mathrm{~m}^{3} / \mathrm{s}$; de 20 anos para vazão de $3,2 \mathrm{~m}^{3} / \mathrm{s}$; de 50 anos para vazão de $2,8 \mathrm{~m}^{3} / \mathrm{s}$, e de 100 anos para vazão de $2,6 \mathrm{~m}^{3} / \mathrm{s}$, gráfico 2 .

Figura 3 - Período de retorno de vazões mínimas, estação Fazenda Letreiro

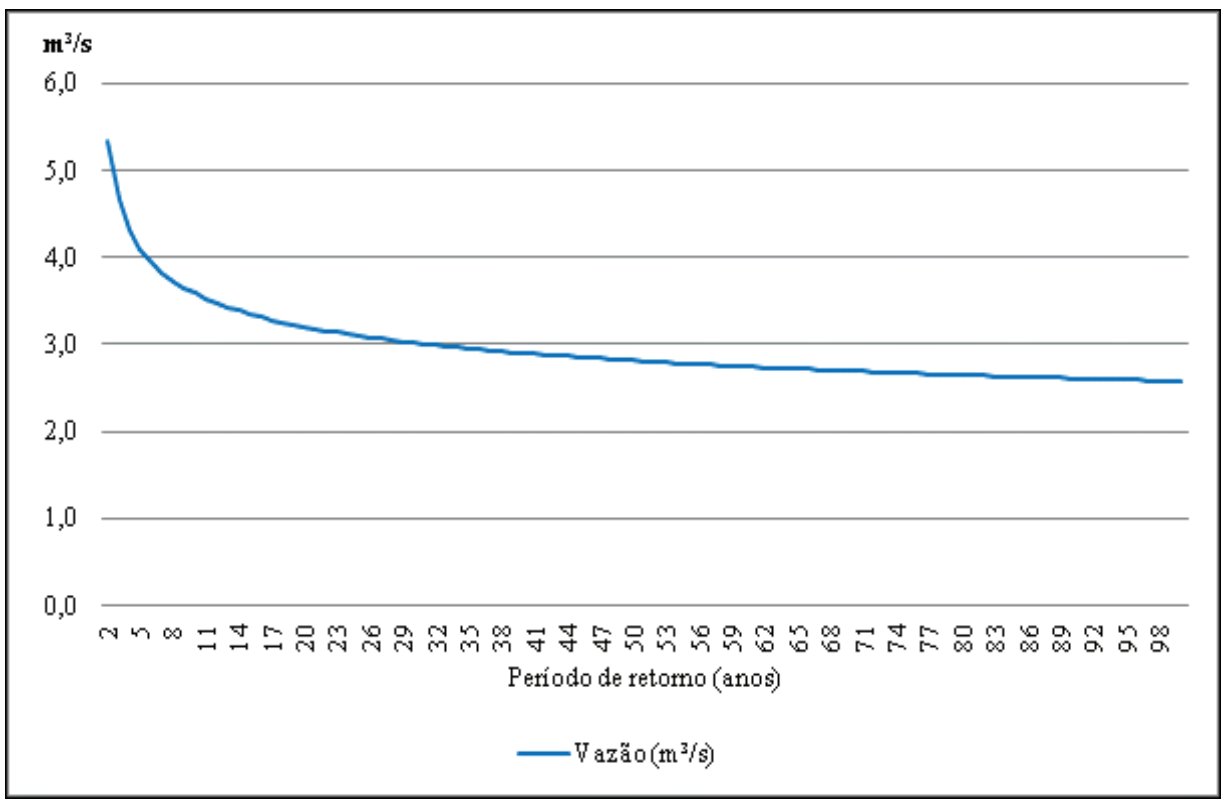

Org. dos autores.

No que se refere à demanda pelo uso de água, na área em questão existem vinte e duas outorgas superficiais. Com relação aos distintos usos, do total requerido, vinte outorgas estão destinadas para atividades agropecuárias, uma para atividade industrial e outra para abastecimento público da cidade de Uberlândia.

Análise de uso intrasetor demonstra que na atividade agropecuária, treze outorgas destinam-se à irrigação, enquanto que as sete outorgas restantes destinam-se a dessedentação de animais e consumo humano em propriedades rurais, ver mapa dos pontos das outorgas na referida bacia (figura 2).

Conforme descrito, $91 \%$ das outorgas conce- didas referem-se a uso da água na agropecuária, no entanto, o volume outorgado por essa atividade representa $10 \%$ do volume total. O uso para o abastecimento público representa apenas uma outorga, porém, com um volume que compreende aproximadamente $90 \%$ do total outorgado. Tal situação se justifica pelo fato de que esta é uma das principais captações de água superficial que serve ao sistema público de abastecimento de água da cidade de Uberlândia, com uma população aproximada de 585.000 habitantes em 2010.

Análise da relação entre a demanda de água e produção hídrica da bacia em período crítico demonstra que há uma probabilidade de que a cada 14 anos ocorra uma situação de escassez hídrica, ou seja, 
a produção hídrica será inferior ao volume outorgado de $3,4 \mathrm{~m}^{3} / \mathrm{s}$. Assim, quando o montante de captação atingir ao outorgado, a retirada de água por demanda será maior que a vazão do rio.

Outros cálculos considerando-se a vazão de referência embasaram outra análise. A vazão de refe- rência adotada atualmente no estado de Minas Gerais dispõe que dada captação não poderá exceder a $50 \%$ da $\mathrm{Q}_{7,10}$ (vazão com período de retorno de 10 anos para a média de sete dias consecutivos dos eventos mais críticos).

Figura 4: Mapa de localização e finalidade das outorgas superficiais, bacia do rio Uberabinha.

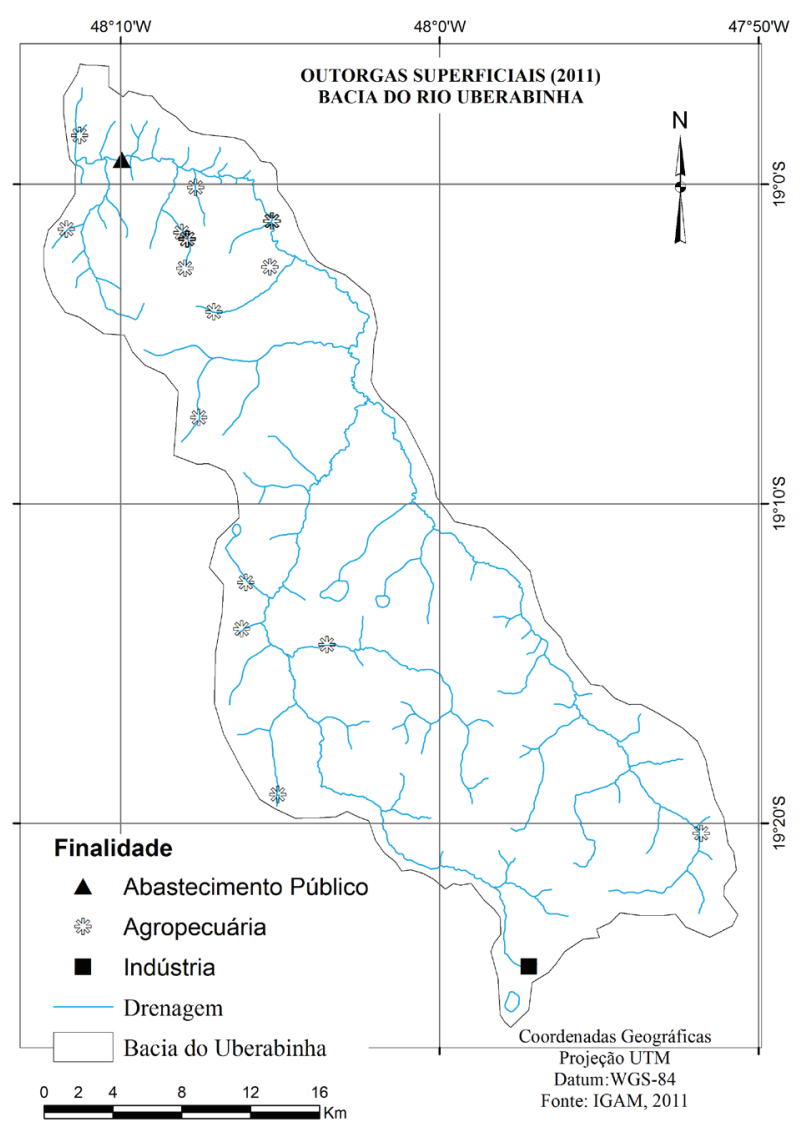

Elaboração dos autores.

A vazão de referência calculada, com base nos dados da série histórica, para toda área da bacia a montante da fluviométrica Fazenda Letreiro, foi de $4,42 \mathrm{~m}^{3} / \mathrm{s}$, logo $50 \%$ desse volume corresponde a uma vazão máxima permitida para captação de $2,21 \mathrm{~m}^{3} / \mathrm{s}$. Assim, análise da relação entre a vazão de referência $\left(50 \%\right.$ do $\left.\mathrm{Q}_{7,10}\right)$ e produção hídrica da seção analisada da bacia, demonstra que há uma probabilidade de num período de mais de cem anos para que a captação, referente à vazão de referência $\left(2,21 \mathrm{~m}^{3} / \mathrm{s}\right)$, seja superior à produção hídrica da bacia, ver comparativo das diversas análises na figura 5 . 
Figura 5 - Comparativo entre volumes outorgados x volumes outorgáveis x vazões mínimas.

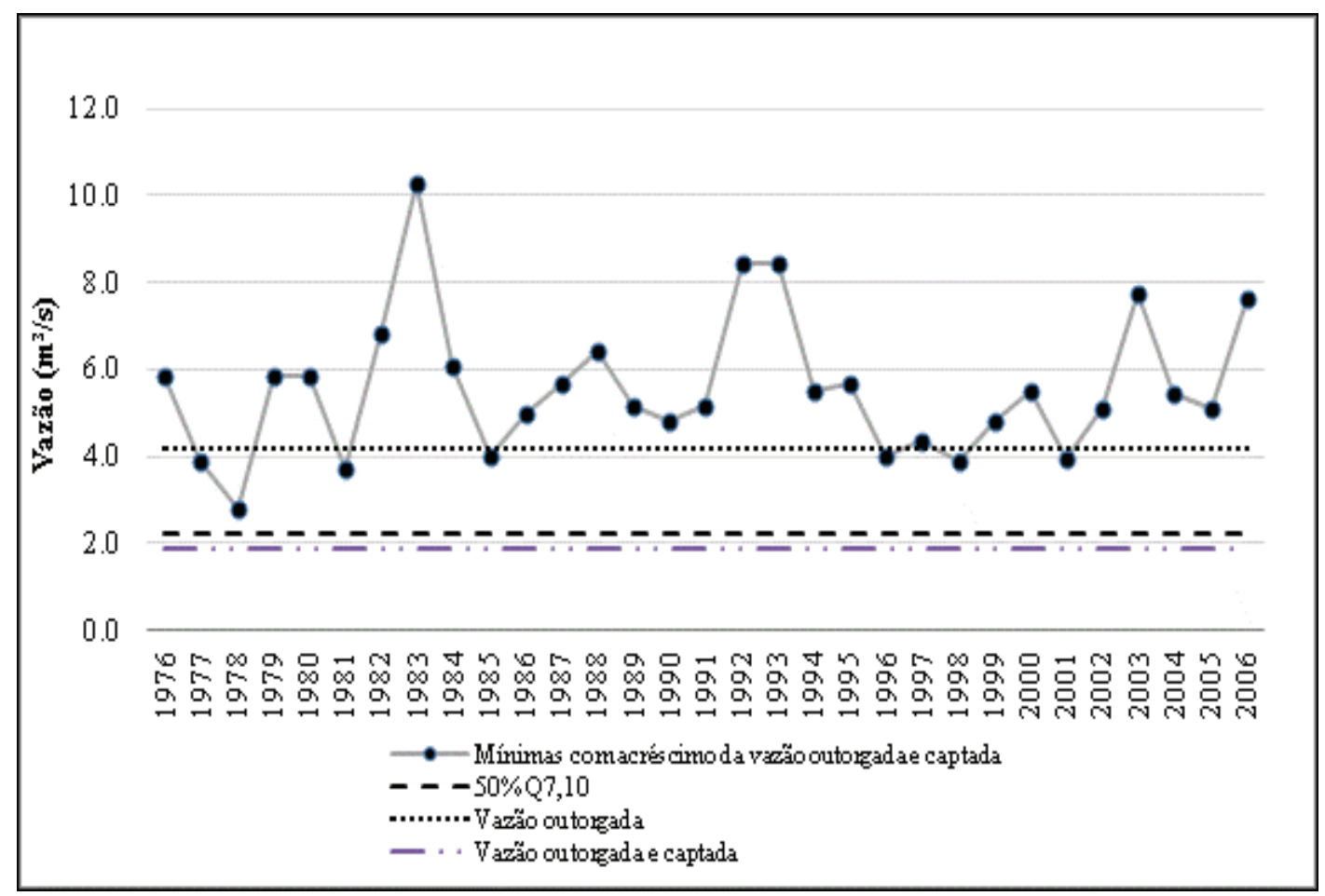

Org. dos autores.

De modo geral, analisando a eficácia do modelo de vazão de referência adotado pelo estado de Minas Gerais, enquanto instrumento de gestão que garanta a capacidade de regulação do sistema hidrológico na seção da bacia analisada, tem-se que este superestima a produção hídrica em detrimento à demanda. $\mathrm{O}$ método de cálculo do $\mathrm{Q}_{7,10}$, considera a média móvel de sete dias dos eventos mínimos (vazões mínimas), com isso, eventos isolados que ocorrem num intervalo inferior a sete dias, são subestimados em função da média móvel. Esta situação está descrita na página acima, no parágrafo sobre análise da relação entre a demanda de água e produção hídrica da bacia.

\section{CONSIDERAÇÕES FINAIS}

Com relação ao objetivo proposto neste trabalho, têm-se que a vazão de referência $\mathrm{Q}_{7,10}$ utilizada como instrumento de outorga no estado de Minas Gerais, pode ser falho quando da ocorrência de eventos isolados, tendo como conseqüência uma situação de conflito pelo uso da água na bacia em questão.
A partir dos resultados obtidos neste trabalho recomenda-se a implantação de um plano de gestão de recursos hídricos na referida bacia, que na atualidade é a única fonte de captação de água para abastecimento público da cidade de Uberlândia.

Tendo em vista o cenário atual, em que o uso predominante da água é para o abastecimento público e que a disponibilidade hídrica na área é insuficiente para atender o volume outorgado, cabe a este setor a iniciativa de mobilização dos usuários de água, buscando a implantação de ações que visem o manejo adequado da bacia contribuindo para a regulação hídrica nos períodos de estiagem. Outra solução para evitar uma situação de conflito é construção de outra estação, de captação de água para abastecimento público, em outra bacia hidrográfica com maior potencial de fornecimento.

Dentre as ações que podem ser implantadas para uma melhor gestão hídrica da área de estudos pode-se destacar a realização de estudos sobre a relação entre o uso do solo e a vazão, instalação e monitoramento de um maior número de estações me- 
teorológicas e hidrométricas, e ainda a implementação de um programas, de valoração econômica, que visem aumentar a produção de água nas propriedades rurais.

\section{REFERÊNCIAS}

AGÊNCIA NACIONAL DE ÁGUAS (ANA). HIDROWEB - Sistema de Informações Hidrológicas. Disponível em $<$ http://hidroweb.ana.gov.br/>, acesso em 15 de junho de 2011.

BACCARO, C.A.D. Estudos geomorfológicos do município de Uberlândia. Sociedade \& natureza, Uberlândia, v. 1, n. 1, p. 17-21, 1989.

CARVALHO, D. F.; SILVA, L. D. B. Hidrologia . Rio de Janeiro: Universidade Federal Rural do Rio de Janeiro, 2006. 115 p. Disponível em <http://www.ufrrj.br/institutos/it/deng/leonardo/it113-hidrologia.htm>, acesso em 10 de nov. de 2011.

COSTA, F. P. M. Utilização de sistemas de informação geográfica na identificação de áreas vulneráveis à contaminação do lençol freático: o caso da bacia do alto e médio curso do rio Uberabinha-MG. 2009. Dissertação (Mestrado em Geografia). Instituto de Geografia, Universidade Federal de Uberlândia, Uberlândia, 2009. 136 f.

CRUZ, J. C. Disponibilidade hídrica para outorga: avaliação de aspectos técnicos e conceituais. 2001. Tese (Doutorado em Engenharia de Recursos Hídricos e Saneamento Ambiental). Instituto de Pesquisas Hidráulicas, Universidade Federal do Rio Grande do Sul, Porto Alegre, 2001. 198 f.

EMBRAPA. Sistema Brasileiro de Classificação de Solos. 2 ed. - Rio de Janeiro: Embrapa Solos, 2006. 306 p.

FELTRAN FILHO, A. A estruturação das paisagens nas chapadas do oeste mineiro. 1997.252 f. Tese (Doutorado em Geografia). FFLCH, Universidade de São Paulo, São Paulo, 1997.

GUIMARÃES, E. C. Geoestatística básica e aplicada. Uberlândia: UFU/FAMAT, 2004. 77 p. (mimeo).
IGAM. Instituto Mineiro de Gestão das Águas. Página na internet. Disponível em $<$ http://www.igam.mg.gov. br>, acesso em 10 de outubro de 2011.

LANNA, A. E. Elementos de estatística e probabilidades. In: TUCCI, C. E. M. (Org.). Hidrologia: ciência e aplicação. Porto Alegre: Editora da UFRGS/ABRH, 2009. P. 79-176.

LIMA, C. R. A. Teoria de erros medidas e gráficos. Juiz de Fora: UFJF/ICE, 2010.37 p. Disponível em: $<$ http://www.fisica.ufjf.br/ cralima/index_arquivos/ Erros/erros.pdf $>$, acesso em 13 março de 2012.

NAGHETTINI, M; PINTO, E. J. A. Hidrologia estatística. Belo Horizonte: CPRM, 2007. 552 p.

OLIVEIRA, L. A.; CAMPOS, J. E. G. Parâmetros hidrogeológicos do Sistema Aqüífero Bauru na região de Araguari/MG: fundamentos para a gestão do sistema de abastecimento de água. Revista Brasileira de Geociências. 34 (2), p.213-218, 2004.

PINTO, N. L. de S. et al. Hidrologia básica. São Paulo: Edgard Blücher, 1976.

SILVEIRA, G. L. et. al. Outorga para o uso dos recursos hídricos: aspectos práticos e conceituais para o estabelecimento de um sistema informatizado. Revista Brasileira de Recursos Hídricos, v. 3, n. 3, p. 5-16, 1998. Disponível em:

http://www.abrh.org.br/novo/arquivos/artigos/v3/ v3n3/outorga.pdf. Acesso em: 12 set. 2011.

SOUSA, H. T. et al. Sistema Computacional para Análise Hidrológicas - SISCAH 1.0. Grupo de Pesquisa em Recursos Hídricos (GPRH), 2009.

TUCCI, C. E. M. ; MENDES, C. A. Avaliação ambiental integrada de bacia hidrográfica. Brasília: MMA, 2006. 302 p.

VILLELA, S. M.; MATTOS, A. Hidrologia aplicada. São Pulo: McGraw-Hill do Brasil, 1975. 